\title{
Exercise and outdoor ambient air pollution
}

\author{
A J Carlisle, N C C Sharp
}

\begin{abstract}
Objectives-To establish by literature survey: (a) levels at which air pollutants are considered damaging to human health and to exercisers in particular; $(b)$ the current ambient levels experienced in the United Kingdom; (c) whether athletes are especially at risk.

Methods-Six major urban air pollutants were examined: carbon monoxide (CO); nitrogen oxides $\left(\mathrm{NO}_{\mathrm{x}}\right)$; ozone $\left(\mathrm{O}_{3}\right)$; particulate matter $\left(\mathbf{P M}_{10}\right)$; sulphur dioxide $\left(\mathrm{SO}_{2}\right)$; volatile organic compounds (VOCs).

Results-CO is detrimental to athletic performance. $\mathrm{NO}_{2}$ is of concern to human health, but outdoor levels are low. $\mathrm{O}_{3}$ poses a potentially serious risk to exercising athletes. Decrements in lung function result from exposure, and there is evidence that athletic performance may be affected. Detrimental effects may occur at low ambient levels, but there is no scientific consensus on this matter. $\mathbf{P} \mathbf{M}_{10}$ is causing concern in the scientific community. Blood lead accumulation during exercise indicates that personal exposure to toxic compounds associated with $\mathbf{P M}_{10}$ may be magnified. Generally, outdoor ambient levels of $\mathrm{SO}_{2}$ are too low to cause a problem to the athlete, except the asthmatic athlete. The few studies on exposure of exercisers to VOCs are reviewed.
\end{abstract}

Conclusions-Athletes and exercisers should avoid exercising by the road side even though levels of the more noxious air pollutants have been controlled in the United Kingdom. $\mathrm{O}_{3}$ is particularly damaging to athletes; it reaches its highest concentrations on hot bright days in rural areas.

(Br f Sports Med 2001;35:214-222)

Keywords: exercise; air pollution

Air pollution continues to be a matter for concern despite falling levels of some of the major pollutants. The aim of this review is to examine six major pollutants in relation to exercise: carbon monoxide (CO); nitrogen oxides $\left(\mathrm{NO}_{\mathrm{x}}\right)$; ozone $\left(\mathrm{O}_{3}\right)$, particulate matter $\left(\mathrm{PM}_{10}\right)$; sulphur dioxide $\left(\mathrm{SO}_{2}\right)$; volatile organic compounds (VOCs). Many of the effects of air pollution on human health have long been established, but no clear consensus has been reached on the effects of ambient air pollution on the exercising athlete and sport performance. A second aim of this review is to relate current ambient air pollution levels to exercising subjects. Maynard $^{1}$ identified a need to understand the effects of long term exposure to current concentrations of air pollutants, and a need to identify groups of the population with greater than average sensitivity to them. As a result of the physiological changes that occur during endurance exercise, it has been postulated that endurance athletes may have greater than average susceptibility and exposure to air pollutants.

Three reasons why athletes are at special risk of inhaling pollutants have been put forward by McCafferty. ${ }^{2}$ Firstly, there is a proportionate increase in the quantity of pollutants inhaled with increases in minute ventilation ( $\dot{\mathrm{V}} \mathrm{E})$ during exercise. Secondly, a larger fraction of air is inhaled through the mouth during exercise, effectively bypassing the normal nasal mechanisms for the filtration of large particles and soluble vapours. Thirdly, the increased airflow velocity carries pollutants deeper into the respiratory tract. Furthermore, pulmonary diffusion capacity has been shown to increase with exercise $\mathrm{s}^{3-6}$; it may therefore be postulated that the diffusion of pollutant gases increases with exercise. For several days after strenuous exercise, nasal mucociliary clearance has been shown to be impaired in long distance runners, ${ }^{7}$ and this is possibly attributable to exposure to air pollution, as stressed by Atkinson. ${ }^{8}$ It could be speculated that such reduced mucociliary clearance may be another contributing factor to the susceptibility of endurance athletes to air pollution, as pollutants that are normally cleared from the respiratory system are instead absorbed.

Inhaled gases can be divided into those that simply equilibrate across the lung-for example, CO-and those that react with components of the respiratory system-for example, $\mathrm{O}_{3}$. The Department of Health's Committee on the Medical Effects of Air Pollutants $(\mathrm{COMEAP})^{9}$ identified the uptake of equilibrating gases as determined by three factors: gas solubility in the blood; cardiac output; the concentration difference between the alveolar space and venous blood, which is dependent on the inhaled concentration of the gas and the 
Table 1 Summary of upper exposure limits of the UK National Air Quality Strategy ${ }^{10}$

\begin{tabular}{|c|c|c|}
\hline \multirow[b]{2}{*}{ Pollutant } & \multicolumn{2}{|c|}{ Upper exposure limit or "standard" } \\
\hline & Concentration & Measured as \\
\hline Benzene & $5 \mathrm{ppb}$ & $\begin{array}{l}\text { Running annual } \\
\text { mean }\end{array}$ \\
\hline 1,3-Butadiene & $1 \mathrm{ppb}$ & $\begin{array}{l}\text { Running annual } \\
\text { mean }\end{array}$ \\
\hline Carbon monoxide & $\begin{array}{l}10 \text { ppm (10 } 000 \\
\text { ppb) }\end{array}$ & Running $8 \mathrm{~h}$ mean \\
\hline Lead & $0.5 \mu \mathrm{g} / \mathrm{m}^{3}$ & Annual mean \\
\hline Nitrogen dioxide & $\begin{array}{l}150 \mathrm{ppb} \\
21 \mathrm{ppb}\end{array}$ & $\begin{array}{l}1 \mathrm{~h} \text { mean } \\
\text { Annual mean }\end{array}$ \\
\hline Ozone & $50 \mathrm{ppb}$ & Running $8 \mathrm{~h}$ mean \\
\hline $\begin{array}{l}\text { Fine particles } \\
\left(\mathrm{PM}_{10}\right)\end{array}$ & $50 \mu \mathrm{g} / \mathrm{m}^{3}$ & Running $24 \mathrm{~h}$ mean \\
\hline Sulphur dioxide & $100 \mathrm{ppb}$ & 15 min mean \\
\hline
\end{tabular}

ventilation rate. A number of important controlling factors determine the uptake of reactive gases in the lung: morphology; physicochemical properties of the gas, tissues, blood, and mucous; pattern of breathing (nasal/oral or oral); ventilatory rate and tidal volume; convective and diffusional patterns of the gas. Clearly, in the absorption of both equilibrating and reactive gases, a number of factors are altered during exercise: cardiac output; pattern of breathing; ventilatory rate; tidal volume; thickness of mucous layer of the lung; possibly gas diffusion patterns.

Table 1 shows the upper exposure limits (or "standards" as they are referred to in the UK National Air Quality Strategy ${ }^{10}$ ) of the major air pollutants in the United Kingdom. In the sections that follow, these will be examined and, where possible, illustrations given of the levels commonly experienced in the United Kingdom (particularly London) and how they may relate to someone who is exercising, both in terms of possible health effects and decrements in athletic performance. The weighting given to each section generally reflects both the severity of the problem and the quantity of research published. Units throughout this review are reported in line with the upper exposure limits as outlined in table 1 . The standards are concentrations over a given period of time, which if exceeded are considered to be unacceptable in terms of human health and/or the environment.

\section{Carbon monoxide}

$\mathrm{CO}$ is a colourless and odourless toxic gas which causes hypoxia by various mechanisms: (a) by the formation of carboxyhaemoglobin (COHb) with an affinity that is 200 times greater than oxygen; (b) by decreasing the delivery of oxygen to the tissues (the haemoglobin oxygen dissociation curve shifts to the left); (c) by inhibiting the action of cytochrome oxidases. Variations in uptake of $\mathrm{CO}$ are thought to be due to physiological variables such as lung capacity, diffusion constant of the lung, and dead space volume. ${ }^{11}$ Ventilation rate is also thought to affect CO uptake. In the $1980 \mathrm{~s}$, the concentration of $\mathrm{COHb}$ in the blood of city dwellers was found to be approximately double that in people living in rural traffic-free areas. ${ }^{11}$ Strenuous exercise in heavy
Table 2 Carbon monoxide health effects for a lightly exercising person ${ }^{22}$

\begin{tabular}{|c|c|c|c|c|}
\hline \multicolumn{2}{|c|}{ Ambient $\mathrm{CO}$} & \multicolumn{3}{|c|}{ Carboxyhaemoglobin (\%) } \\
\hline$p p m$ & $m g / m^{3}$ & After $1 \mathrm{~h}$ & After $8 \mathrm{~h}$ & At equilibrium \\
\hline 100 & 117 & 3.6 & 12.9 & 15 \\
\hline 60 & 70 & 2.5 & 8.7 & 10 \\
\hline 30 & 35 & 1.3 & 4.5 & 5 \\
\hline 20 & 23 & 0.8 & 2.8 & 3.3 \\
\hline 10 & 12 & 0.4 & 1.4 & 1.7 \\
\hline
\end{tabular}

traffic for 30 minutes can increase the level of $\mathrm{COHb} 10$-fold, which is the equivalent of smoking 10 cigarettes. $^{12}$

There is no doubt that $\mathrm{CO}$ is detrimental to athletic performance and there is much experimental evidence of this. ${ }^{12-18}$ With CO in the bloodstream, less $\mathrm{O}_{2}$ is released from haemoglobin to myoglobin, and therefore, to compensate, the heart must work harder and beat more frequently. Maximum cardiac output and maximal arteriovenous difference are lowered, resulting in a decrease in maximum oxygen uptake $\left(\dot{\mathrm{V}}_{2} \mathrm{MAX}\right)$ and work output. ${ }^{19}$ The formation of $\mathrm{COHb}$ is reversible, and exposure to clean air removes most of the gas from the body, with a half life of three to four hours.

The risk of $\mathrm{CO}$ poisoning in joggers and cyclists in areas of traffic congestion is difficult to predict because the concentration and movement of $\mathrm{CO}$ depend on prevailing wind and temperature. Nonetheless, one study found levels of $4-6 \% \mathrm{COHb}$ in the blood of city joggers and cyclists, a level comparable to that found in chronic cigarette smokers ${ }^{17}$ and known to result in decreased exercise tolerance. ${ }^{20}$ The effects of raised $\mathrm{COHb}$ on exercise performance have indicated a significantly lower $\dot{\mathrm{V}}_{2} \mathrm{MAX}$, anaerobic threshold, and oxygen pulse $\left(\dot{\mathrm{VO}}_{2}\right.$ /heart rate), and a significantly higher heart rate and pulse pressure. ${ }^{15}$ The rate of $\mathrm{COHb}$ formation in exercising humans exposed to $\mathrm{CO}$ was studied to improve prediction of CO poisoning. ${ }^{14}$ The existing prediction model, known as the CFK equation (developed by Coburn et $a l^{21}$ ), was tested and found to be useful overall, with a sigmoidal rate of appearance of $\mathrm{COHb}$ as previous observations indicated. ${ }^{14}$

The World Health Organisation (WHO) calculated the relation between $\mathrm{CO}$ concentration and blood $\mathrm{COHb}$ for a lightly exercising subject (table 2 ). $\mathrm{COHb}$ values are reduced by a factor of two for a person at rest and increased by a similar factor by heavy exercise. Thus a heavily exercising subject can expect to have $1.6 \% \mathrm{COHb}$ after one hour in $20 \mathrm{ppm}$ $\mathrm{CO}$. Levels of $2.7 \% \mathrm{COHb}$ and upwards result in evidence of impaired behaviour. ${ }^{22}$

In the past, accumulated levels of $\mathrm{CO}$ posed a significant health risk to athletes in this country, and one of us noted incidents of collapse in London to Brighton relay races in the 1950s. CO levels experienced in the United Kingdom today have been improved by the use of catalytic converters in motor vehicles, which oxidise vehicular exhaust $\mathrm{CO}$ to $\mathrm{CO}_{2}$. The improvement has been offset by the increase in the total number of motor vehicles, so overall total emissions have remained relatively stable in recent years. The UK National Monitoring 


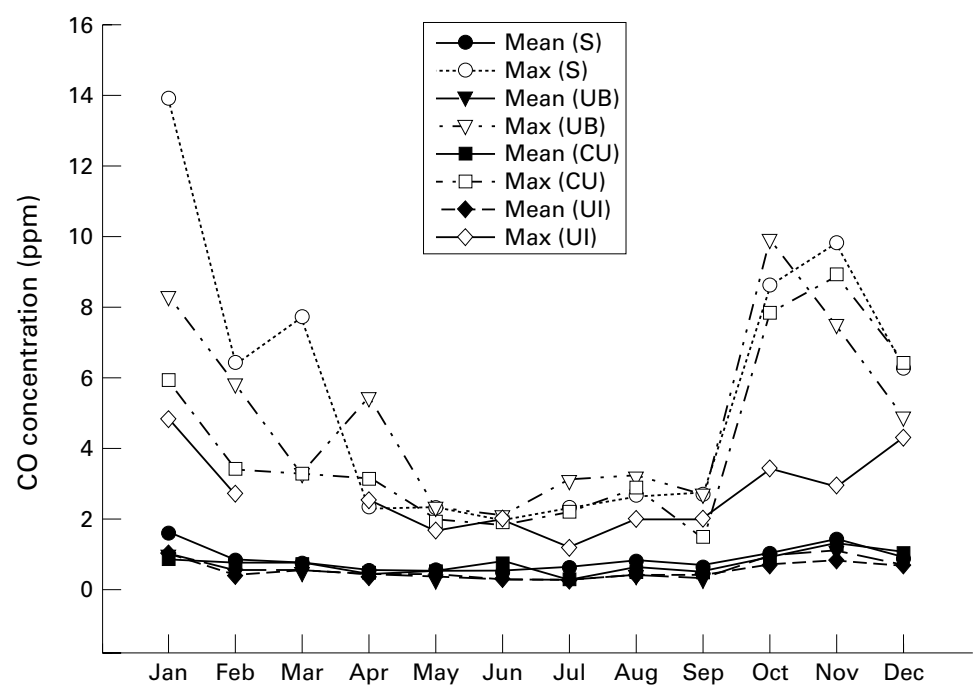

Figure 1 Arithmetic mean and maximum hourly average monthly statistics of 1997 CO levels at four British sites from the UK National Monitoring Network ${ }^{10}: S$, suburban; UB, urban background; CU, central urban; UI, urban industrial.

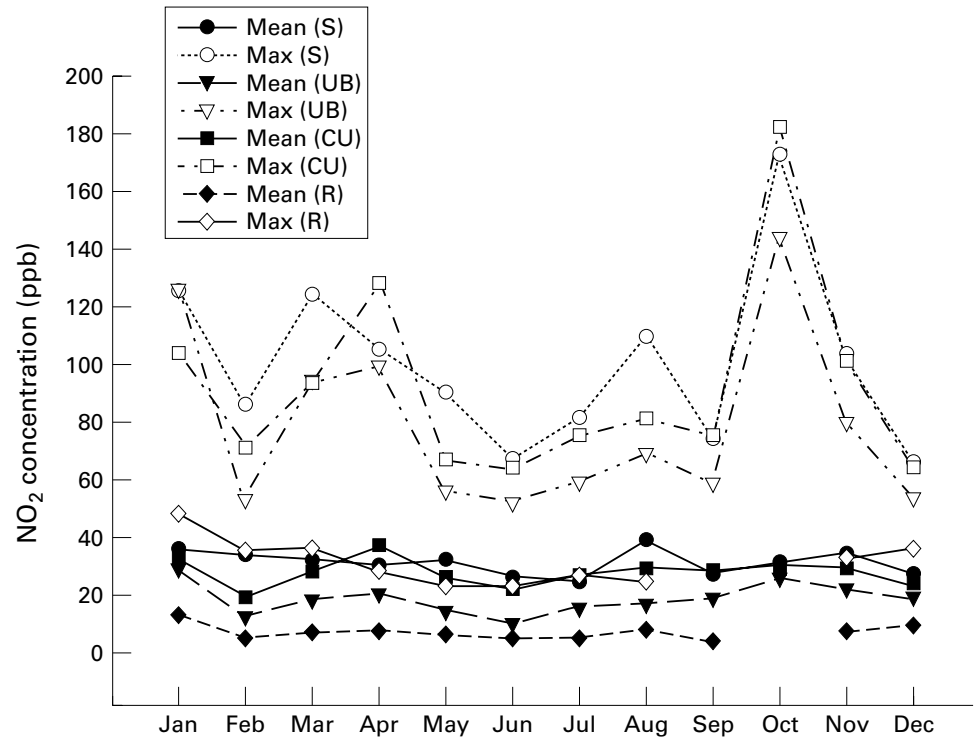

Figure 2 Arithmetic mean and maximum hourly average monthly statistics of $1997 \mathrm{NO}$ levels at four British sites from the UK National Monitoring Network ${ }^{10}: S$, suburban; UB, urban background; $C U$, central urban; $R$, rural.

Network notes that levels of CO are low (fig 1), and the standard for $\mathrm{CO}(10 \mathrm{ppm}$ eight hour running mean) was seldom exceeded in 1997. Continual monitoring does show high momentary peaks in $\mathrm{CO}$ concentration, hence it is prudent always to train away from roads. For comparison, mean (SE) levels of 13.8 (1.7) ppm have been reported inside a car, $44.0(7.3)$ $\mathrm{ppm}$ in an underground car park, and 10.9 (0.9) $\mathrm{ppm}$ in a public house. ${ }^{23}$

\section{Nitrogen oxides}

The two principle oxides of nitrogen, $\mathrm{NO}$ and $\mathrm{NO}_{2}$, are often considered together and known as $\mathrm{NO}_{\mathrm{x}}$ (pronounced "knocks"), despite their quite different physical properties, chemical affinities, and environmental impacts. The main source of $\mathrm{NO}_{\mathrm{x}}$ is road traffic. $\mathrm{NO}$ is photochemically oxidised to $\mathrm{NO}_{2}$, and the following photochemical equilibrium exists between the relevant gases: $\mathrm{NO}+\mathrm{O}_{3} \rightarrow \mathrm{NO}_{2}+\mathrm{O}_{2}$
Of the two oxides of nitrogen, $\mathrm{NO}_{2}$ has a much higher toxicity. Its distribution has been shown to follow the expected pattern-that is, areas of the United Kingdom with high $\mathrm{NO}_{2}$ concentrations correlate well with the geographical distribution of the major urban conurbations and major emission sources. ${ }^{22}$ Discussion will focus on $\mathrm{NO}_{2}$ in this section.

$\mathrm{NO}_{2}$ is of concern to human health as it is soluble and can be absorbed by the mucous lining of the nasopharyngeal cavity, where it is converted to nitrous and nitric acids. The oxidant properties of $\mathrm{NO}_{2}$ after acute exposure at levels of 5000-10 $000 \mathrm{ppb}$ can cause respiratory illness, such as pharyngeal irritation, cough, and dyspnoea. ${ }^{11}$ Resistance to respiratory infection can also be impaired by $\mathrm{NO}_{2}$ exposure below $500 \mathrm{ppb} .{ }^{11} \mathrm{NO}_{2}$ levels in urban environments are usually below $150 \mathrm{ppb}$. The UK National Air Quality standard for $\mathrm{NO}_{2}$ is $150 \mathrm{ppb}$, measured as an hourly mean. Figure 2 illustrates the 1997 monthly statistics for $\mathrm{NO}_{2}$ from the National Monitoring Network. Long term exposure may have a subtle effect on children. A meta-analysis of 11 epidemiological studies suggested that the chance of infection in the lower respiratory tract may be $20 \%$ greater for children with prolonged exposure to $\mathrm{NO}_{2}$ at a concentration of $16 \mathrm{ppb} .{ }^{20}$ Asthmatics have been shown to experience significant increases in airway resistance with short term $\mathrm{NO}_{2}$ exposures of around $500 \mathrm{ppb}$. Nonasthmatics experience the same changes at $\mathrm{NO}_{2}$ levels of about 1000 ppb. ${ }^{11}$ Four daily sequential exposures to $2 \mathrm{ppm} \mathrm{NO}_{2}$ for four hours resulted in persistent neutrophilic inflammation in the airways of healthy nonsmoking subjects. Changes in pulmonary function attenuated with repeated exposures. ${ }^{24}$ Potentially serious effects may occur, but it has generally been found that outdoor levels are low; there can be greater danger from some indoor environments such as gas heated homes and poorly ventilated residences inside which fires are lit such as are found in underdeveloped countries.

\section{Ozone}

$\mathrm{O}_{3}$ forms in the atmosphere through very complex chemical interactions and equilibria between hundreds of different hydrocarbons and radicals and $\mathrm{NO}$ and $\mathrm{NO}_{2}$, all requiring photochemical energy. Daily ambient $\mathrm{O}_{3}$ levels in the United Kingdom rarely exceed $100 \mathrm{ppb},{ }^{9}$ at which concentration significant decrements in lung function (forced vital capacity (FVC); forced expiratory volume in one second $\left(\mathrm{FEV}_{1}\right)$; mean forced expiratory flow between 25 and $75 \%$ of FVC $\left(\mathrm{FEF}_{25-75}\right)$; airway resistance $\left(R_{\text {AW }}\right)$ ) have been observed at an exercise intensity equating to a $\dot{V}_{E}$ of 70.0 litres/min. ${ }^{25}$ Figure 3 shows monthly statistics for $\mathrm{O}_{3}$ in 1997. As expected, $\mathrm{O}_{3}$ levels were higher in the summer than the winter. In large hot cities such as Los Angeles, a diurnal pattern of $\mathrm{O}_{3}$ concentration is observed, peaking around midday well after the morning rush hour and when solar radiation is at its highest. $\mathrm{O}_{3}$, however, is a transboundary 


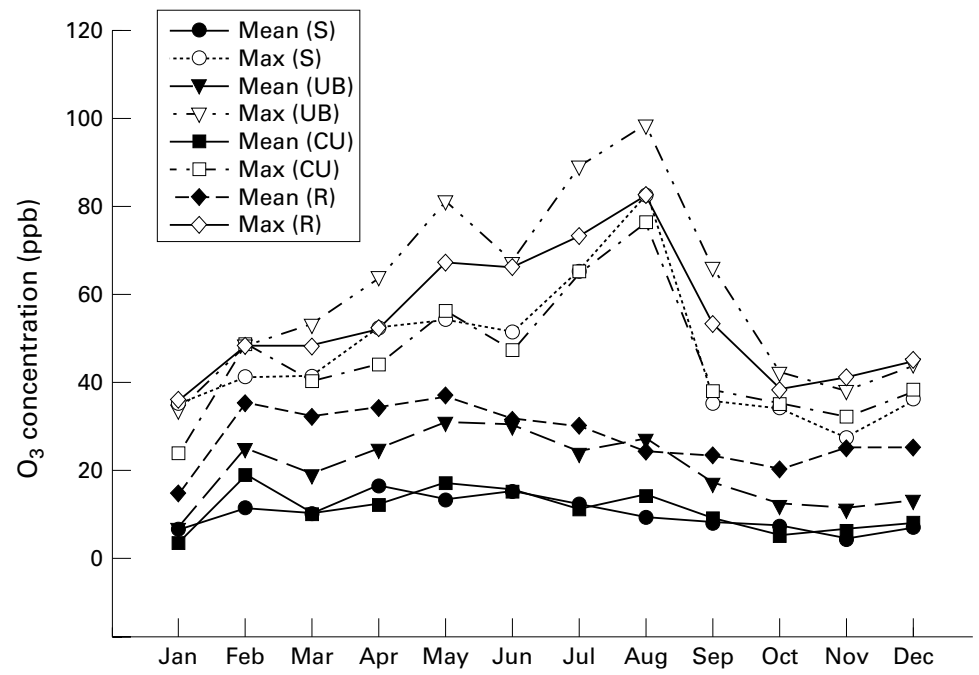

Figure 3 Arithmetic mean and maximum hourly average monthly statistics of $1997 \mathrm{O}$ levels at four British sites from the UK National Monitoring Network ${ }^{10}: S$, suburban; UB, urban background; $C U$, central urban; $R$, rural.

pollutant and travels considerable distances. As such, and contrary to conventional wisdom, it is predominantly a rural pollutant.

$\mathrm{O}_{3}$ exposure above $120 \mathrm{ppb}$ is known to have detrimental effects on health. Symptoms are nose and throat irritation, coughing, wheezing, shortness of breath, and an inability to take deep breaths because of substernal chest pain or constriction. Nausea and headache occur if $\mathrm{O}_{3}$ exposure is sufficient. Abnormalities of pulmonary function usually parallel the severity of symptoms and are accelerated by exercise. Data obtained in the 1970s and 1980s confirm the observation that decreased FVC and $\mathrm{FEV}_{1}$ are consistent responses to $\mathrm{O}_{3}$ exposure. FVC and $\mathrm{FEV}_{1}$ are easily measured and yield quantifiable results. Concentration-response regression curves of lung measurements in exercising subjects show progressively increased decrements in measurements of lung function with increasing exercise intensity. ${ }^{25}$ Other forced and inspired flow rates, inspiratory capacity and total lung capacity (TLC), are also affected, and there is increased $R_{A W}$ and residual volume.

It has been suggested that $\mathrm{O}_{3}$ inhalation stimulates receptors located in the smooth muscle layers of the upper airways. ${ }^{26}$ Contraction of the inspiratory muscles is limited by the non-myelinated $\mathrm{C}$ fibre afferent nerves of vagal origin, which may act through axonal reflex connections or through spinal reflexes. The net effect on the human lung is involuntary inhibition of full inspiration, reduction of transpulmonary pressure and inspiratory capacity, and increased flow resistance. There is an associated decrease in maximal expiratory flow rates, TLC, and vital capacity accompanied by substernal pain and coughing. Research has shown an influx of inflammatory cells into the pulmonary tissue. ${ }^{27}$ Pretreatment with ibuprofen has been shown to alleviate symptoms produced by $\mathrm{O}_{3}$ exposure. ${ }^{27}$ Folinsbee ${ }^{28}$ points out that some research has shown that pretreatment with the cyclo-oxygenase inhibitor indometacin abolishes $\mathrm{O}_{3}$ induced decrements in pulmonary function. Pretreatment with salbutamol has been found to be ineffective in reducing or eliminating pulmonary discomfort or respiratory dysfunction in cyclists exposed to $\mathrm{O}_{3}{ }^{29}{ }^{29}$ This observation on exercising subjects has been supported elsewhere. ${ }^{26}$ The decreased tidal volume and increased respiratory rate associated with $\mathrm{O}_{3}$ exposure cause relative hyperventilation. High environmental temperature $\left(35^{\circ} \mathrm{C}\right)$ has been shown to exacerbate further the negative impact of $\mathrm{O}_{3}$ on lung function. $^{30} 31$

Athletes are vulnerable to the effects of inhaled $\mathrm{O}_{3}$ because of their exercise patterns. ${ }^{31}$ $\dot{\mathrm{V}} \mathrm{E}$ and $\dot{\mathrm{V}}_{2}$ are both dramatically increased with the onset of physical activity, whether it is heavy short term or less intense and prolonged, including training, warm up, and competition. Long distance runners perform at exercise intensities as great as $90 \%$ of their $\dot{\mathrm{V}}_{2} \mathrm{MAX}$, which may correspond to a $\dot{V} E$ of over 100 litres/min, and they may maintain this for over an hour. Elite endurance cyclists may similarly maintain a $\dot{V} E$ of 80 litres/min during hour long races. Resting $\dot{V}_{E}$ is by comparison $<10$ litres $/ \mathrm{min}$. There is high individual variability in response to $\mathrm{O}_{3}$ exposure, showing that the effects of $\mathrm{O}_{3}$ are a consequence of multiple factors within the pulmonary tree. ${ }^{28}$ Many studies were published in the 1960s, 1970s, and 1980s and have been reviewed elsewhere ${ }^{31}$.

The respiratory discomfort associated with $\mathrm{O}_{3}$ exposure may cause decreased maximal work performance. Ten highly trained endurance athletes were randomly exposed to filtered air, and to $0.12,0.18$, and $0.24 \mathrm{ppm} \mathrm{O}_{3}$ while performing a one hour competitive simulation protocol on a cycle ergometer. ${ }^{32}$ They all completed the protocol when exposed to filtered air, whereas one, five, and seven subjects did not complete the protocol when exposed to $0.12,0.18$, and $0.24 \mathrm{ppm}(120,180$, and 240 ppb) $\mathrm{O}_{3}$ respectively. Statistical analysis indicated a significant $(\mathrm{p}<0.05)$ increase in the inability of subjects to complete the competitive simulations with increasing $\mathrm{O}_{3}$ exposure when compared with filtered air. There was also a significant and progressive decrement in pulmonary function. Respiratory discomfort has been observed to contribute significantly to an increase in overall relative perceived exertion. ${ }^{33}$ Furthermore, the increased breathing frequency and decreased tidal volume associated with $\mathrm{O}_{3}$ exposure has been postulated to be behavioural, as it reduces the sensation of pain. ${ }^{28}$ A physiological mechanism is involved: $\mathrm{O}_{3}$ stimulates the non-myelinated bronchial $\mathrm{C}$ fibres involved in the reflex which changes breathing patterns to rapid and shallow breathing. ${ }^{28}$ It is possible that people become habituated to $\mathrm{O}_{3}$ and that acclimatisation by athletes may occur.

Levels of $\mathrm{O}_{3}$ lower than $60 \mathrm{ppb}$ have been shown to significantly affect lung function. ${ }^{34}$ $\mathrm{FVC}, \mathrm{FEV}_{1}, \mathrm{FEF}_{25-75}$, and peak expiratory flow rate were recorded before and after exercise in healthy young men. Data were collected in the field and related to $\mathrm{O}_{3}$ concentrations obtained from the nearest stations of the National Monitoring Network. $\mathrm{O}_{3}$ concentrations were 


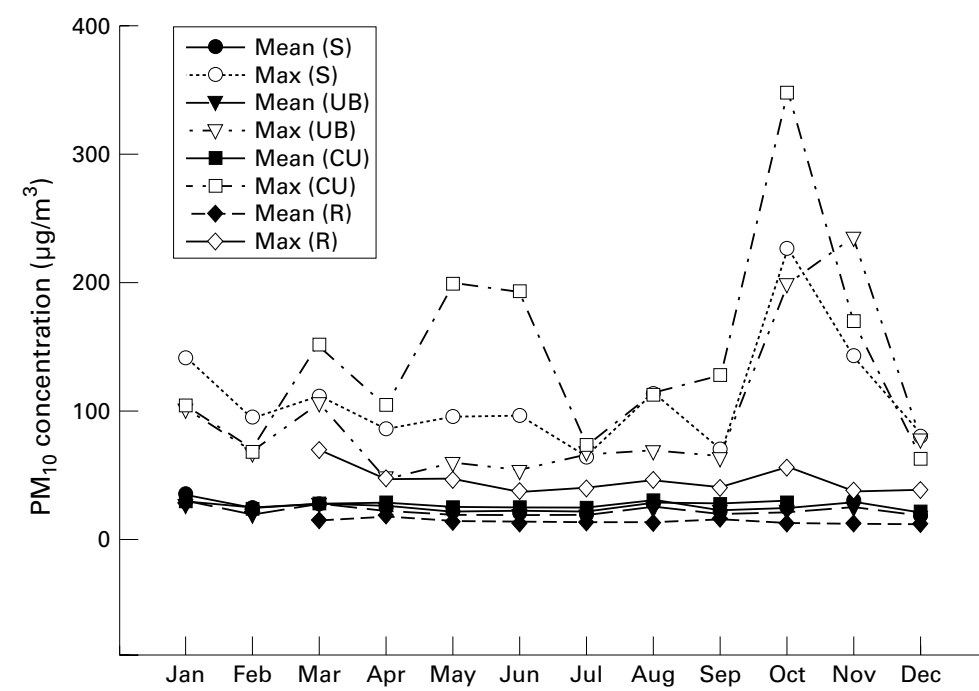

Figure 4 Arithmetic mean and maximum hourly average monthly statistics of 1997 levels of particulate matter $\left(P M_{10}\right)$ at four British sites from the UK National Monitoring Network $^{10}: S$, suburban; UB, urban background; CU, central urban; $R$, rural.

low, with an average of $43 \mathrm{ppb}$ and a maximum of $97 \mathrm{ppb}$. Results of the study show that there was a significant association between $\mathrm{O}_{3}$ and a decline in lung function over a race or training period. Other confounding environmental factors, such as temperature, $\mathrm{PM}_{10}, \mathrm{SO}_{2}$, and $\mathrm{NO}_{2}$, were considered. Temperature, it was argued, did not magnify the alterations in lung function observed in this study, as $80 \%$ of the data were obtained at a temperature below $22^{\circ} \mathrm{C}$. Concentrations of $\mathrm{SO}_{2}$ and $\mathrm{NO}_{2}$ were low during the period of observation and it was considered unlikely that they had any confounding effects. No ambient air levels of $\mathrm{PM}_{10}$ were available, so no adjustment could be made. These observations, coupled with the finding that the removal of data obtained at $\mathrm{O}_{3}$ concentrations higher than $60 \mathrm{ppb}$ still left significant effects, were taken as an indication that $\mathrm{O}_{3}$ at very low concentrations resulted in changes in lung function during exercise. However, this observation is not supported by other studies, ${ }^{25} 3135$ in which the maximum length of exposure was two hours, the studies were conducted in pollution chambers, $\mathrm{O}_{3}$ was studied singly, and cumulative effects were not looked for. It therefore seems likely that the findings of Brunekreef et $a l^{34}$ are more reflective of ambient exposure, although it is questionable whether the decrements in lung function would surface as decrements in exercise performance.

$\mathrm{O}_{3}$ is an unpleasant gas, and its effects are detrimental to athletic performance if exposure is sufficiently high. Levels of $\mathrm{O}_{3}$ experienced in the United Kingdom, however, remain low most of the time, and therefore $\mathrm{O}_{3}$ is unlikely to cause problems here. The outlook in this country is that $\mathrm{O}_{3}$ levels will increase by about 3-4 ppb from current levels of around 10-15 $\mathrm{ppb}^{36}$

\section{Particulate matter}

Particulate matter comprises solid (soluble or insoluble) or liquid material present in the air in particles small enough to remain in suspension for some hours or days. They are typically less than $10 \mu \mathrm{m}$ in diameter and are therefore often referred to as $\mathrm{PM}_{10}$. Particles of this size are capable of entering the respiratory tract and reaching the deeper parts of the lung. A significant proportion of $\mathrm{PM}_{10}$ is less than $2.5 \mu \mathrm{m}$ in diameter $\left(\mathrm{PM}_{2.5}\right)$, and it is particles of this size that are most likely to be deposited in the respiratory tract, and, once in the alveoli, diffusive deposition increases. Particles of diameter of less than $0.5 \mu \mathrm{m}$ are least likely to be deposited in the respiratory tract, as they are too small to either impact on, or diffuse to, the walls effectively and are exhaled before they can be deposited.

Particulate pollution peaks during smogs. Winter smogs are a result of build up of local emissions in cold still weather, and summer smogs are caused by the action of sunlight on emissions accompanied by a build up of $\mathrm{O}_{3}$. There is a synergistic interaction between $\mathrm{PM}_{10}, \mathrm{SO}_{2}$, and water vapour. ${ }^{22}$ Water vapour and $\mathrm{SO}_{2}$ are absorbed on to soot particles while they are present together in the ambient air, and trace metals such as vanadium in the particles catalyse the formation of sulphuric acid. On inhalation, these particles transport the sulphuric acid deep into the lungs, where the gas exchange surfaces are damaged and the capacity for oxygen exchange is decreased. This synergism between particles and $\mathrm{SO}_{2}$ is such that it has been incorporated into legislation, with recommendations for lower tolerable levels of $\mathrm{SO}_{2}$ when the particulate levels are above a certain concentration: the European Community, for example, specifies an annual mean of $120 \mu \mathrm{g} / \mathrm{m}^{3} \mathrm{SO}_{2}$ unless the particle concentration is less than $40 \mu \mathrm{g} / \mathrm{m}^{3}$, when the upper limit for $\mathrm{SO}_{2}$ is reduced to $80 \mu \mathrm{g} / \mathrm{m}^{3}$.

During the 1990s in the United States and Canada, very many studies indicated a link between airborne particulate matter and mortality. ${ }^{37}$ In response to growing concern in the United Kingdom on this matter, the government invited COMEAP to advise on the health effects of non-biological particles, ${ }^{38}$ and the Expert Panel on Air Quality Standards (EPAQS) to recommend air quality standards for particles. ${ }^{39}$ The recommended upper limit of $\mathrm{PM}_{10}$ is currently $50 \mu \mathrm{g} / \mathrm{m}^{3}$ as a running 24 hour average in the United Kingdom, which is seldom exceeded in London, where smoke control exists, as illustrated by fig 4 . In areas of Britain where there is no smoke control, high levels could build up in the winter months when temperature inversion occurs. COMEAP's report on non-biological particles and health recognised that exercise may have a variable effect on particle deposition depending on particle size and pattern of respiration. ${ }^{38}$ It may be that, at increased airflow velocities, the pollutants are not deposited but simply exhaled. As yet the question of pollutant deposition in the respiratory tract during exercise remains unanswered and uncertain. What is certain is that the increased airflow velocity (a consequence of pronounced increases in $\dot{\mathrm{V}}$ ) bypasses much of the normal nasal filtration and carries pollutants deeper into the respiratory tract; hence there is a proportionate increase in the quantity of pollutants inhaled. 
Table 3 One hour averaged results for concentrations of particulate matter of diameter less than $10 \mu \mathrm{m}\left(P M_{10}\right)$ by route $^{41}$

\begin{tabular}{llll}
\hline \multirow{4}{*}{ Route } & \multicolumn{2}{l}{$P M_{10}\left(\mu g / m^{3}\right)$} & \\
\cline { 2 - 4 } & fan & May & Aug \\
\hline Inner city & $17-62$ & $90-194$ & $92-162$ \\
Rural & $16-38$ & $71-166$ & - \\
\hline
\end{tabular}

There have been very few studies examining the relation between exercise and $\mathrm{PM}_{10}$ inhalation. Personal sampling of $\mathrm{PM}_{10}$ pollution in a group of people working close to traffic has shown it to be significantly higher than static measurements of area, ${ }^{40}$ and from this it can be surmised that the same would be true for athletes training by the roadside. Weather conditions have a pronounced effect on $\mathrm{PM}_{10}$ exposure-for example, rainy weather and high wind speeds result in lower $\mathrm{PM}_{10}$ concentrations. ${ }^{41}{ }^{42}$ Equipment for personal air sampling was supplied to volunteers in a study on exposure of cyclists, car drivers, and pedestrians in Amsterdam to pollution. ${ }^{4}$ Thoracic fraction $\mathrm{PM}_{10}$ was monitored, and within this fraction the content of lead and six (carcinogenic) polyaromatic hydrocarbons was determined. A comparison was made between rural and inner city routes. Table 3 shows the results for $\mathrm{PM}_{10}$. $\mathrm{PM}_{10}$ concentration was on average about seven times lower on a quiet open rural route than on an inner city route. Similar results were gained from a study on commuting by bicycle in Southampton. ${ }^{42}$ The findings of these two studies indicate that personal exposure to $\mathrm{PM}_{10}$ of people exercising at the roadside in the city is higher than that of the sedentary person and those exercising in rural locations. Although this is unlikely to affect athletic performance, it has potentially significant effects on health. Exposure to human carcinogens associated with $\mathrm{PM}_{10}$ is considered negligible by the UK government. $^{38}$

Lead is associated with particulates. After inhalation, it is absorbed into the bloodstream with potentially toxic effects on a wide range of body tissues. ${ }^{43}$ Figure 5 presents the results of a South African study on ultra-marathon runners before and after government legislation halved lead content of petrol. Significant differences were found in mean blood lead level $(p=0.01)$ between the subjects examined in 1984 and 1990, reflecting the fall in lead content of petrol. On average, the blood lead levels in city runners had decreased from 52 to 10 $\mu \mathrm{g} / \mathrm{dl}$ of blood (2.5 to $0.5 \mu \mathrm{mol} / \mathrm{l}$ ), and the level in rural athletes had decreased from 20 to 8.5 $\mu \mathrm{g} / \mathrm{dl}$. No significant difference was found among the 1990 urban trainers, rural trainers, and urban controls. A significant difference was shown, however, between the 1990 rural trainers and 1984 remote rural controls, the 1990 city trainers and 1984 remote rural controls, and the 1990 controls and 1984 rural trainers. ${ }^{44}$ This indicates that lead is accumulated faster in runners because of the higher exercising intensity. A study of British competitive cyclists aimed to establish the influence of training environment and racing discipline (time trialists or road racers) on blood lead level. ${ }^{43}$ No significant difference was found in blood lead level between controls and experimental groups, but this may have been due to the very small sample size. Correlations between blood lead level and training type were examined, and the results indicated that training type influenced blood lead level (table 4).

$P M_{10}$ is inhaled deeper into the respiratory tract during exercise, but, as yet, it is uncertain whether exercise increases deposition. The research on blood lead indicates that lead (which is associated with particulate matter) may accumulate to higher concentrations in people who train in an urban compared with a rural environment. A significant correlation has also been shown between number of training hours and blood lead accumulation. It would seem therefore that runners and cyclists experience increased exposure to lead. Could it be that personal exposure to other toxic compounds associated with $\mathrm{PM}_{10}$ is also increased?

\section{Sulphur dioxide}

The effects of $\mathrm{SO}_{2}$ have been clearly documented elsewhere. ${ }^{13} 2845$ The gas readily dissolves in water and tends to be removed from the inspired air stream by the moist surfaces of the upper airways, especially the nasal mucosa. The threshold level for the effects of $\mathrm{SO}_{2}$ on lung function lies between 1000 and $2000 \mathrm{ppb}$ in normal healthy adults. Above the threshold, resting subjects exposed to $\mathrm{SO}_{2}$ experience bronchospasm. During exercise, as oral breathing replaces nasal breathing, a corresponding increase in penetration of $\mathrm{SO}_{2}$ into the intrathoracic airways exacerbates the effect. ${ }^{45}$ The inspiration of $5000 \mathrm{ppb} \mathrm{SO}_{2}$ during exercise results in a significantly higher rate of mucociliary clearance than in exercising controls breathing air. ${ }^{13}$ This is a high dose, and $\mathrm{SO}_{2}$ is unlikely to occur in the UK environment at such a level, but the finding has important implications because mucociliary clearance is an important aspect of the respiratory system's defence against microorganisms and particulate pollution. It is also of note that exercise alone increases the rate of mucociliary clearance. Today's legislation requires clean technological processes, and, in the United Kingdom, $\mathrm{SO}_{2}$ emissions have been reduced to well below the threshold level. The recommended air quality standard in Britain for $\mathrm{SO}_{2}$ is $100 \mathrm{ppb}$ measured over a 15 minute averaging period. Figure 6 shows the monthly statistics for $\mathrm{SO}_{2}$ in 1997.

Asthmatics are generally ten times more sensitive to $\mathrm{SO}_{2}$ than non-asthmatics, especially when exercising. The symptoms associated with asthma are exacerbated by $\mathrm{SO}_{2}$. At concentrations of $500 \mathrm{ppb} \mathrm{SO}_{2}$, exercising asthmatics experience pronounced changes (as much as $100 \%$ ) in airways resistance after as little as five minutes of exercise. ${ }^{46}$ Decreases in $\mathrm{FEV}_{1}$ of $50-60 \%$ are seen in most exercising asthmatics exposed to $0.25 \mathrm{ppm} \mathrm{SO}_{2}{ }^{28}$ Wheezing, chest tightness, and dyspnoea are experienced. Fortunately, all the symptoms and changes in lung function associated with exercising in $\mathrm{SO}_{2}$ can be rapidly reversed by 


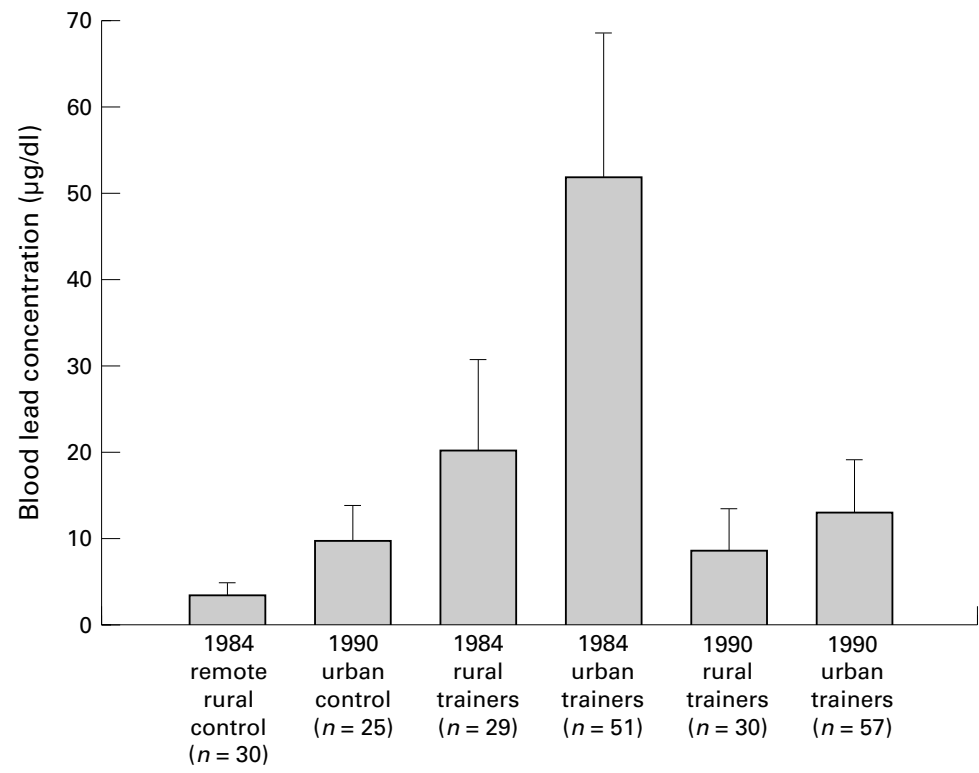

Figure 5 Mean (SD) blood lead level in competitors in the 1984 and 1990 Comrades marathon of South Africa. ${ }^{44}$

Table 4 Correlation coefficients between blood lead levels and amount of training and racing in each environment for the pooled sample $(n=10)^{43}$

\begin{tabular}{ll}
\hline Training characteristic & Correlation $(r)$ \\
\hline Total training & $0.637(\mathrm{p}<0.05)$ \\
Urban training & $0.704(\mathrm{p}<0.05)$ \\
Dual carriageway training & $0.646(\mathrm{p}<0.05)$ \\
Rural training & $0.011(\mathrm{p}>0.1)$ \\
\hline
\end{tabular}

treatment with a $\beta_{2}$ adrenergic agonist-for example, salbutamol or terbutaline. Cromolyn sodium or $\beta$-agonists have been used prophylactically. ${ }^{47}$ Histamine release from mast cells in the respiratory tissue is stimulated by $\mathrm{SO}_{2}$. Smooth muscle contraction and increased resistance to expiratory airflow are produced and reflected in measures of FVC and $\mathrm{FEV}_{1}$. Cromolyn sodium blocks histamine release thereby minimising bronchoconstriction, whereas a $\beta$-agonist produces relaxation of airway smooth muscle.

Although $\mathrm{SO}_{2}$ is clearly an important irritant for exercising asthmatics and may cause problems for the asthmatic athlete, it is unlikely to be of concern to the athlete with normal lungs at current ambient levels. Air temperature and humidity influence the degree of symptoms experienced, with cold dry air producing a faster and more intense response to $\mathrm{SO}_{2}$ than warm moist air. ${ }^{18}$ It is possible that $\mathrm{SO}_{2}$ may be one of the triggers for exercise induced bronchospasm. The overall incidence of exercise induced bronchospasm across all sports and sexes in a recent survey of Olympic winter sport athletes was reported as $23 \% .^{48}$

\section{Volatile organic compounds}

The general category of VOCs consists of many chemicals, including non-methane hydrocarbons (for example, alkanes, alkenes, and aromatics), halocarbons (for example, trichloroethylene), and oxygenates (alcohols, aldehydes, and ketones). The emission into the British environment of well over two million tonnes of
VOCs per year is similar in magnitude to that of $\mathrm{SO}_{2}$ and $\mathrm{NO}_{\mathrm{x}}{ }^{22}$. There is a preponderance of carcinogens among VOCs-for example, benzene, polyaromatic hydrocarbons, 1,3butadiene, many of the halocarbons. Owing to the carcinogenicity of benzene and polyaromatic hydrocarbons, no safe levels are recommended by WHO. The published standards of the UK National Air Quality Strategy are $5 \mathrm{ppb}$ for benzene as a running annual mean, and 1 ppb for 1,3-butadiene as a running annual mean (table 1 ).

The area of exercise and VOCs inhalation and possible accumulation appears to have been largely overlooked, and there are few studies on exposure to VOCs during exercise. Exposure of cycling commuters (average journey time 35 minutes) to various VOCs was studied in Southampton. ${ }^{42}$ Eighteen VOCs were identified and quantified. $\dot{\mathrm{V}} \mathrm{E}$ was not measured, but it was taken into account in the conclusions of the study, and the group recognised it as a significant factor in terms of personal exposure. They found significantly increased levels of exposure to aromatic VOCs, but not to hydrocarbons and other measured VOCs, when commuting by bicycle during peak traffic periods. Weather conditions affected results, with lower exposure on windy days. In the Netherlands, personal exposure to pollutants was compared in people commuting by car and bicycle by urban and rural routes (average journey time one hour; sampling time 30 minutes). ${ }^{41} \dot{\text { VE }}$ was measured continuously with a gas meter, and heart rate was recorded. Ambient air was sampled at a constant flow rate of 1 litre/min through active charcoal tubes. Benzene, toluene, and xylene were analysed by gas chromatography. It was concluded that car drivers are exposed to higher concentrations of VOCs than cyclists, but, because of the magnitude of the increase in $\dot{V}$, uptake of benzene, toluene, and xylene in cyclists sometimes approached that of car drivers. The ratio of urban to rural personal exposure levels was calculated for cyclists, and found to be 1:5 for benzene and toluene, and 1:10 for xylene. Weather patterns affected results; time weighted exposure to VOCs was higher in August for cyclists. The limited data available on VOCs in relation to exercise indicate that cycling in urban areas results in higher personal exposure to VOCs than cycling in rural areas. Extrapolation to runners is probably justified. VOCs are important and often overlooked pollutants, some of which are carcinogens.

\section{Conclusions and advice}

Advice to those exercising is of course to stay away from traffic. There is an exponential decline in concentrations of many air pollutants with increasing distance from the busy road. It is advisable to exercise whenever possible in open rural or park land. High momentary peaks can occur in the levels of any of the pollutants. Try to avoid the rush hour when $\mathrm{NO}_{\mathrm{x}}, \mathrm{CO}$, and VOCs are likely to accumulate. If it is cold and smoggy, exercise indoors. Windy weather tends to dilute and disperse the pollutants. Check the pollution forecasts and 


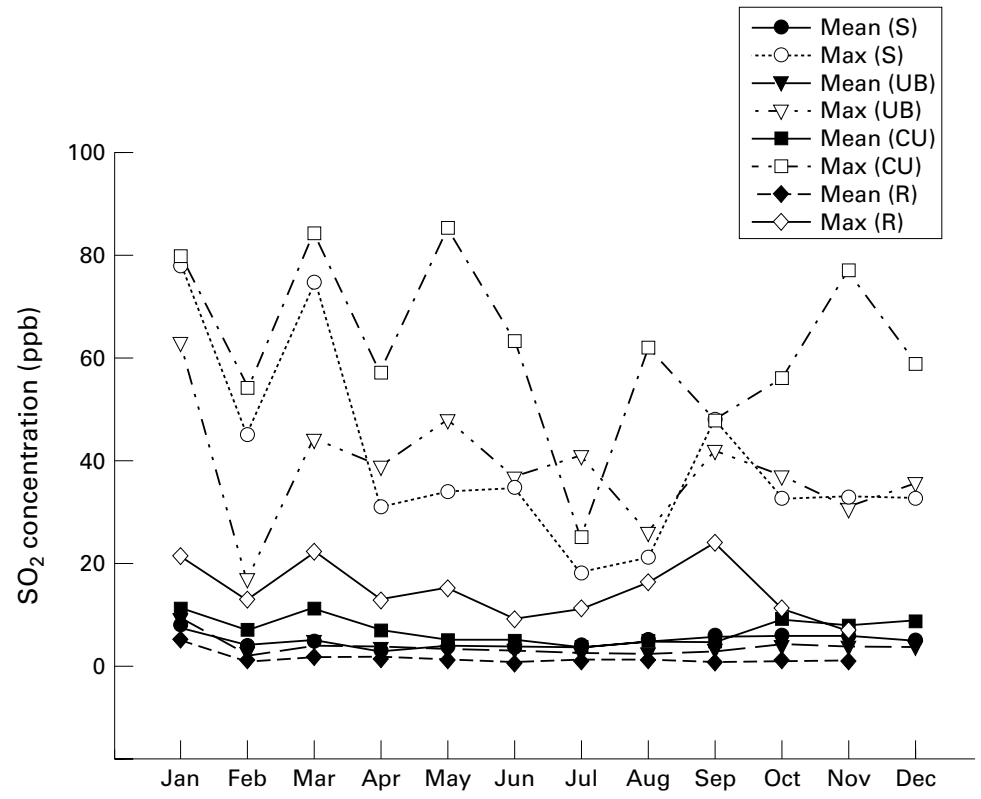

Figure 6 Arithmetic mean and maximum hourly average monthly statistics of $1997 \mathrm{SO}_{2}$ levels at four British sites from the UK National Monitoring Network ${ }^{10}: S$, suburban; UB, urban background; $C U$, central urban; $R$, rural.

bulletins and take heed of any warnings. Particular care is advised when travelling. Some countries do not have the same stringent regulations to control pollution as the United Kingdom, and the air quality could be considerably different as a result. Climatic and geographic conditions can result in much higher accumulations of pollutants, as in Los Angeles, for example, so even in "developed" countries dangerously high pollution levels may occur. Indoor environments pose more risk of $\mathrm{CO}$ poisoning than the open road, with higher levels found inside a pub and a car than by a school kerbside. ${ }^{23}$ Athletes should therefore keep away from smoky environments and avoid car journeys in congested traffic before competition and training, as the temporarily accumulated CO may reach levels that will have detrimental effects on athletic performance. On hot bright days in the United Kingdom, elevated levels of $\mathrm{O}_{3}$ may occur, which can be avoided by running/cycling in the early morning or late evening. Check the pollution bulletins and forecasts for occasional high levels in photochemical smogs during summer inversions. Be especially careful in rural areas where elevated $\mathrm{O}_{3}$ levels may occur. $\mathrm{SO}_{2}$ is unlikely to be of concern to the athlete with normal lungs at current ambient levels, but it clearly is an important irritant for exercising asthmatics, and may cause problems for the asthmatic athlete. Asthmatics are advised to take their (inhaler) medication before exercise, and to carry an inhaler with them when exercising. There is little risk of damage from exposure to $\mathrm{NO}_{2}$ while street training in the London urban atmosphere, although there may be a greater risk in rural areas. The advice above all is to keep away from busy roads.

Diet may be important. There is some evidence from animal studies that vitamin $\mathrm{E}$ can prevent some morphological and biochemical effects of $\mathrm{O}_{3}$ exposure, although there is little supporting evidence from studies on humans. ${ }^{45}$ A leading authority finds that antioxidant supplements reduce the detrimental effects of $\mathrm{O}_{3}$, possibly by decreasing formation of lipoperoxides, ozonoides, and oxidation products. $^{28}$ Recent epidemiological research has found evidence of an interaction between $\mathrm{NO}_{2}$ exposure and significantly decreased plasma $\beta$-carotene levels in supplemented subjects. ${ }^{49}$ It would be advisable for all athletes to ensure that they consume adequate dietary $\beta$-carotene and other antioxidants as fresh vegetables and fruit each day, and/or by taking dietary supplement(s).

Although it is logical to study air pollutants singly, ambient air pollutants do not exist in isolation; they constitute a cocktail, and synergism may exist between them. Environmental conditions and the weather affect levels of pollution exposure and physiological responses. Some studies have shown personal exposure to be significantly different from the levels indicated by ambient monitoring carried out by the local authorities in the United Kingdom. This consideration is highly relevant to the training athlete who may also suffer greater exposure for the reasons outlined in the introduction. The length of time spent exercising is another very important factor. Ultra-marathon runners and others participating in long endurance events - for example, walking and cycling - are likely to be most at risk from the negative and harmful effects of pollution exacerbated by exercise. Future research could be directed at studying the collective effects of pollutants and personal exposure, and the adoption of risk assessment in relation to exposure to air pollution could be a way forward to ensure adequate long term health protection for the athlete.

We thank the reviewers for the obvious trouble that was taken with the manuscript, and also Drs Helen Carter and Jonathan with the manuscript, and also Drs Helen Carter and
Horner for their initial comments on the manuscript.

1 Maynard RL. Air pollution research in the United Kingdom. Occup Environ Med 1999;56:647.

2 McCafferty WB. Air pollution and athletic performance. Springfield: Charles C Thomas, 1981

3 Turcotte RA, Perrault H, Marcotte JE, et al. A test for measurement of pulmonary diffusion capacity during high intensity exercise. $\mathcal{F}$ Sports Sci 1992;10:229-35.

4 Turcotte RA, Kiteala L, Marcotte JE, et al. Exercise-induced oxyhemoglobin desaturation and pulmonary diffusiong capacity during high-intensity exercise. Eur $\mathcal{F}$ Appl Physiol 1997;75:425-30.

5 Stokes DL, Macintyre NR, Nadel JA. Non-linear increases in diffusing capacity during exercise by seated and supine subjects. $\mathcal{F}$ Appl Physiol 1981;51:858-63.

6 Fisher JT, Cerny FJ. Characteristics of adjustment of lung diffusiong capacity to work. $\mathcal{F}$ Appl Physiol 1982;52:1124-7.

7 diffusiong capacity to work. F Appl Physiol 1982;52:1124-7. Muns G, Singer P, Wolf F, et al. Impaired nasal muciliary
clearance in long-distance runners. Int f Sports Med 1995; clearance in 10.

16:209-13.
8 Atkinson, G. Air pollution and exercise. Sports Exercise and Injury 1997;3:2-8.

9 COMEAP for the DoH. Asthma and air pollutants. London: HMSO, 1995.

10 National Air Quality Information Archives. http:// www.aeat.co.uk/netcen/airqual/

11 Lee K, Yanagisawa Y, Spengler JD, et al. Carbon monoxide and nitrogen dioxide exposures in indoor ice skating rinks. 7 Sports Sci 1994;12:279-83.

12 Nicholson JP, Case DB. Carboxyhaemoglobin levels in New York City runners. Physician and Sportsmedicine 1983;11: 135-8.

13 Horvarth S. Impact of air quality on exercise performance. Exerc Sports Sci Rev 1981;9:265-96.

14 Tikusis P, Kane DM, McLellan TM, et al. Rate of formation of carboxyhaemoglobin in exercising humans exposed to carbon monoxide. F Appl Physiol 1992;72:1311-19. 
15 Hopkins MG. Passive smoking as determined by salivary cotinine and plasma carboxyhaemoglobin levels in adults and school-aged children of smoking and non-smoking parents: effects on physical fitness. Ann Sports Med 1990;5 96-104.

16 Anderson O. Dodging the deadly cocktail. Running magazine. 1989 Oct: 42,43 , and 64

17 Gong H Jr, Krishnareddy S. How pollution and airborne allergens affect exercise. Physician and Sportsmedicine 1995; 23:35-42.

18 Stamford B. Exercise and air Pollution. Physician and Sportsmedicine 1990;18:153-4.

19 Ekblom B, Huot R, Stein EM. Effect of changes in arterial oxygen content on circulation and physical perfomance. $f$ Appl Physiol 1975:39:71-5.

20 Pribyl CR, Racca J. Toxic gas exposures in ice arenas. Clin $\mathcal{f}$ Sports Med 1996;6:232-6.

21 Coburn R, Forster RE, Kane PB. Consideration of the physiology and variables that determine the blood carboxyphysiology and variables that determine the blood carboxy1899-910.

22 Colls J. Air pollution, an introduction. London: E \& FN Spon,

23 Horner J. Carbon monoxide: the invisible killer. $f R$ Soc Health 1998;118:141-4.

24 Blomberg A, Krishna MT, Helleday R, et al. Persistent airway inflammation but accomodated antioxidant and lung function responses after repeated daily exposure to nitrogen dioxide. Am ₹ Respir Crit Care Med 1999;159:53643.

25 Hazucha MJ. Relationship between ozone exposure and pulmonary function changes. $\mathcal{F} \mathrm{Appl}$ Physiol 1987;62:167180.

26 Hazucha MJ, Bates DV, Bromberg PA. Mechanism of action of ozone on the human lung. F Appl Physiol 1989;67:153541

27 Hazucha MJ, Madden M, Pape G, et al. Effects of cyclo-oxygenase inhibition on ozone-induced respiratory inflammation and lung function changes. Eur f Appl Physiol inflammation and

28 Folinsbee LJ. Air pollution: acute and chronic effects. Proceedings of Marathon Medicine 2000. London: The Royal Proceedings of Marathon Medic
Society of Medicine, 2001.

29 McKenzie DD, Stirling SF, Allen M. The effects of salbuta$\mathrm{mol}$ on pulmonary function in cyclists exposed to ozone: a pilot study. Canadian fournal of Sport Sciences 1987;12:46-

30 Raven PB. Questions and answers. Fournal of Cardiac Rehabilitation 1982;2:411-14

31 Gong Jr H. Effects of ozone on exercise performance. $\mathcal{F}$ Sports Med 1987;27:21-9.

32 Schelegle ES, Adams WC. Reduced exercise time in competitive simulations consequent to low level ozone exposure. Med Sci Sports Exerc 1986;18:408-14.
33 Mihevic PM, Gliner JA, Horvarth SM. Perception of effort and respiratory sensitivity during exposure to ozone. Ergoand respiratory sensitivity

34 Brunekreef B, Hoek G, Breugelmans O, et al. Respiratory effects of low-level photochemical air pollution in amateur cyclists. Am f Crit Care Med 1994;150:962-6.

35 McDonnell WF, Stewart PW, Andreoni S, et al. Prediction of Ozone-induced $\mathrm{FEV}_{1}$ changes. Effects of concentration, duration and ventilation. Am f Crit Care Med 1997;156: $715-22$.

36 Stedman JR, Linehan E, King K. Quantification of the health effects of air pollution in the UK for the Review of the National Air Quality Strategy. A Report for The Department of the Environment, Transport and the Regions. Jan 1999.

37 Reichhardt T. Weighing the health risks of airborne particulates. Environ Sci Technol 1995;29:360A-4A.

38 COMEAP for the DoH. Non-biological particles and health. London: HMSO, 1995.

39 DoE, DoH and DoT. Health Effects of Particles. The Government's preliminary response to the reports of the Committee on the Medical Effects of Air Pollutants and the Expert Panel on Air Quality Standards. London: HMSO,

40 Watt $M$, Godden $\mathrm{D}$, Cherrie J, et al. Individual exposure to particulate air pollution and its relevance to thresholds for health effetcs: a study of traffic wardens. Occup Environ Med 1995;52:790-2

41 van Wijnen JH, Verhoeff AP, Jans HWA, et al. The exposure of cyclists, car drivers and pedestrians to traffic-related air pollutants. Int Arch Occup Environ Healt. 1995;67:187-93.

42 Bevan MAJ, Procter CJ, Baker-Rogers J, et al. Exposure to carbon monoxide, respirable suspended particulates and volotile organic compounds. Environ Sci Technol 1991;25: 788-91.

43 Atkinson G, Maclaren D, Taylor C. Blood levels of British competitive cyclists. Ergonomics 1994;37:43-8.

44 Grobler SR, Maresky LS, Kotze TJvW. Lead reduction of petrol and blood lead concentration of athletes. Arch Environ Health. 1992;47:139-42.

45 Pierson WE, Covert DS, Koenig JQ, et al. Implications of air pollution effects on athletic performance. Med Sci Sport Exerc 1986;18:322-7.

46 Linn WS, Venet TG, Shamoo DA, et al. Respiratory effects of sulfar dioxide in heavily exercising asthmatics. Am Rev Respir Dis 1983;127:278-83.

47 Folinsbee LJ, Raven PB. Exercise and air pollution. 7 Sports Sci 1984;2:57-75.

48 Wilber RL, Rundell KL, Szmedra L, et al. Incidence of exercise-induced bronchospasm in Olympic winter sport athletes. Med Sci Sports Exerc 2000;32:732-7.

49 Bernard N, Saintot M, Astre C, et al. Personal exposure to nitrogen dioxide pollution and effect on plasma antioxidants. Arch Environ Health 1998;53:122-8.

Take home message

The respiratory physiology of exercise suggests that athletes and other exercisers may experience magnified exposure to ambient air pollution.

\section{Rapid responses}

Letters on the following papers have been published recently as rapid responses on the BfSM website. To read these letters visit www.bjsportmed.com and click on "Read eLetters":

Indoor rock climbing: who gets injured? DM Wright, TJ Royle, T Marshall. Br f Sports Med 2001;35:181-5

Diabetes and extreme altitude mountaineering. K Moore, C Thompson, R Hayes. Br $\mathcal{f}$ Sports $M e d$ $2001 ; 35: 83$

Evidence-based sports medicine. P McCrory. Br F Sports Med 2001;35:79-80.

Methods of appointment and qualifications of club doctors and physiotherapists in English professional football: some problems and issues. I Waddington, M Roderick, R Naik. Br f Sports Med 2001;35:48-53.

Medical supervision of sport diving in Scotland: reassessing the need for routine medical examinations. S Glen, S White, J Douglas. Br F Sports Med 2000;34:375-8.

Getting started-a review of physical activity adoption studies. AL Dunn. Br f Sports Med 1996:30:193-9.

If you would like to post an electronic response to these or any other articles published in the journal, please go to the website, access the article in which you are interested, and click on "eLetters: Submit a reponse to this article" in the box in the top right hand corner. 